\title{
Localization of nitric oxide synthase activity in unfertilized oocytes and fertilized embryos during preimplantation development in mice
}

\author{
A. Nishikimi ${ }^{1}$, T. Matsukawa², K. Hoshino², S. Ikeda², Y. Kira ${ }^{1}$, \\ E. F. Sato ${ }^{1}$, M. Inoue ${ }^{1}$ and M. Yamada ${ }^{2 *}$ \\ ${ }^{1}$ Department of Biochemistry and Molecular Pathology, Osaka City University Medical School, \\ Osaka 545-8585, Japan; and '2 Laboratory of Reproductive Physiology, Division of Applied \\ Biosciences, Graduate School of Agriculture, Kyoto University, Kyoto 606-8502, Japan
}

Changes in the activities of nitric oxide synthase (NOS) during embryonic development, and the distribution of endothelial nitric oxide synthase (eNOS) and inducible nitric oxide synthase (iNOS) isoforms were examined in unfertilized mouse oocytes at the second meiotic metaphase (MII) stage and in fertilized mouse embryos during preimplantation development. In addition, the effects of NOS inhibitors on mouse preimplantation development in vitro were investigated. The activities of NOS in MII oocytes and fertilized embryos during the preimplantation period were determined by NADPHdiaphorase staining. Although NOS activity was detected in unfertilized MII oocytes, the intensity of staining was much weaker than that of fertilized embryos at the one-cell stage. There was a decrease in NOS activity in embryos from the four-cell to the eight-cell stage; however, NOS activity

\section{Introduction}

Nitric oxide $(\mathrm{NO})$ is a ubiquitous, endogenously produced free radical, which is involved in a wide variety of biological processes, such as vasodilation, neurotransmission, blood clotting and host defence mechanisms (Ignarro, 1990; Moncada et al., 1991). NO is produced by conversion of oxygen and L-arginine to $\mathrm{NO}$ and L-citrulline. This reaction is catalysed by nitric oxide synthase (NOS), of which there are three different isoforms: endothelial nitric oxide synthase (eNOS), inducible nitric oxide synthase (iNOS) and neuronal nitric oxide synthase (nNOS) in almost all types of cell (Griffith and Stuehr, 1995). eNOS and nNOS are constitutive and $\mathrm{Ca}^{2+}$-calmodulin-dependent isoforms that are involved in cellular signalling. iNOS is an inducible isoform produced only in response to a stimulus and is not $\mathrm{Ca}^{2+}$ dependent.

NO plays important roles in many events during embryonic development, such as regulation of egg activation at fertilization in sea urchin oocytes (Kuo et al., 2000),

*Correspondence

Email: yamada@jkans.jkans.kais.kyoto-u.ac.jp increased again in embryos at the morula stage, particularly in the inner cell population. In the expanded blastocysts, staining was confined to the inner cell mass. Immunocytochemical staining showed that eNOS and iNOS were expressed in the cytoplasm of oocytes and embryos during the preimplantation period, and eNOS was also distributed in the nuclei of the embryos. When one-cell embryos were treated with $1 \mathrm{mmol} \mathbf{N}^{\omega}$-nitro-L-arginine methyl ester (L-NAME) $\mathrm{I}^{-1}$, their development in vitro was arrested at the two-cell stage. This inhibition of develop-

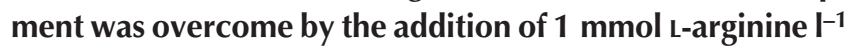
to the medium. These observations indicate that nitric oxide plays an important role as a diffusible regulator of cell proliferation and differentiation, especially at the developmental transition from the two-cell to the four-cell stage during preimplantation development of mice. and regulation of the balance between cell proliferation and differentiation in Drosophila embryo development (Kuzin et al., 1996). In addition, several studies have reported the activities of the NO-related enzyme, NOS, in preimplantation development (Gouge et al., 1998) and implantation in mammals (Novaro et al., 1997; Biswas et al., 1998; Gagioti et al., 2000; Saxena et al., 2000). Although it has been reported that eNOS and iNOS are expressed in blastocysts collected from the uterus of delayed-implanting mice, and preovulatory and ovulatory oocytes JablonkaShariff and Olson, 1997, 1998; Gouge et al., 1998), expression and activities of NOS in preimplantation embryos and the role of $\mathrm{NO}$ in preimplantation development has not been fully elucidated. In the present study, the presence and changes of NOS activities, and the distribution of eNOS and iNOS isoforms were examined in mouse embryos during preimplantation development and in unfertilized mouse oocytes at the second metaphase (MII) stage using NADPHdiaphorase histochemistry and immunofluorescence staining, respectively. Because NOS and NADPH diaphorase activities are induced by different properties of the same enzyme molecule, NADPH diaphorase activity can be used as a marker for NOS (Wang et al., 1995). 


\section{Materials and Methods}

\section{Chemicals}

Antibodies and blocking peptides against eNOS and iNOS were purchased from Santa Cruz Biotechnology (Santa Cruz, CA). NOS inhibitors, $N^{\omega}{ }^{\omega}$-nitro-L-arginine-methyl ester (L-NAME), L- $N^{5}$-(1-iminoethyl)-ornithine (L-NIO) and aminoguanidine were purchased from Sigma (St Louis, $\mathrm{MO})$. Biotin-conjugated secondary antibody and fluorescein isothiocyanate (FITC)-conjugated streptavidin were purchased from DAKO (Glostrup). Other reagents were purchased from Wako Pure Chemical Industries Ltd (Osaka).

\section{Oocyte and embryo collection and culture}

ICR female mice (aged 4-6 weeks) were superovulated by injections of 5 iu equine chorionic gonadotrophin (eCG) followed by 5 iu hCG 48 h later. At 16 h after hCG injection, unfertilized MII oocytes were collected from the oviducts by scratching the ampullae using a hypodermic needle. Fertilized one-cell embryos were collected from the ampullae of oviducts of superovulated females that had been mated with the same strain of male at $20 \mathrm{~h}$ after hCG injection. The cumulus cells were removed by digestion with $0.1 \%(\mathrm{w} / \mathrm{v})$ hyaluronidase for approximately $5 \mathrm{~min}$. Embryos were then cultured in potassium simplex optimized medium (KSOM) (Erbach et al., 1994) at $37^{\circ} \mathrm{C}$ under $5 \%$ $\mathrm{CO}_{2}$ in air. Embryos at the two-cell, four-cell, eight-cell, morula and blastocyst stages were collected after 18-22 h of culture (38-42 h after hCG injection), 44-46 h of culture (64-66 h after hCG injection), 56-61 h of culture (76-81 h after hCG injection), 66-71 h of culture (86-91 h after hCG injection) and 92-96 h of culture (112-116 h after hCG injection), respectively.

In an experiment to examine the effects of the NOS inhibitors L-NAME, L-NIO and aminoguanidine on the development of mouse embryos, one-cell embryos were cultured for 4 days in KSOM alone or in medium containing $1 \mathrm{mmol} \mathrm{L}^{-N A M E ~}{ }^{-1}, 10 \mathrm{mmol}_{\mathrm{L}-\mathrm{NIO} \mathrm{I}}^{-1}$ or $2 \mathrm{mmol}$ aminoguanidine $\mathrm{I}^{-1}$ with or without $1 \mathrm{mmol}$ L-arginine $\mathrm{I}^{-1}$, at $37^{\circ} \mathrm{C}$ under $5 \% \mathrm{CO}_{2}$ in air. Development of embryos to the two-cell, four-cell, morula and blastocyst stages was examined at day 4 of culture. Embryos at the four-cell stage were cultured in KSOM with or without $1 \mathrm{mmol}$ L-NAME I-1 to examine the effect of L-NAME on the development in vitro of embryos to the morula and blastocyst stages after day 2 of culture.

Mice were anaesthetized with ether and killed by cervical dislocation. All procedures involving animals were approved by Kyoto University Animal Care and Use Committee.

\section{NADPH-diaphorase histochemistry}

Unfertilized MII oocytes and embryos were fixed in $0.2 \%$ (v/v) glutaraldehyde in PBS for $5 \mathrm{~min}$, rinsed twice in PBS and incubated for $30 \mathrm{~min}$ at $37^{\circ} \mathrm{C}$ in $0.1 \mathrm{mmol}$ Tris- $\mathrm{HCl} \mathrm{I-1,}$ $\mathrm{pH} 7.2$, containing $1 \mathrm{mmol} \beta-\mathrm{NADPH} \mathrm{I}^{-1}, 0.2 \mathrm{mmol}$ nitro- blue tetrazolium $\mathrm{I}^{-1}$ and $0.2 \%$ (v/v) Triton-X100. The oocytes and embryos were rinsed twice in PBS and mounted on glass slides. Omitting $\beta$-NADPH from the incubation solution served as a control for the specificity of the reaction.

Embryos at the one-cell stage were cultured in vitro for $20 \mathrm{~h}$ in medium with or without $1 \mathrm{mmol}$ L-NAME I-1. Embryos that developed to the two-cell stage after $20 \mathrm{~h}$ of culture were stained for NADPH-diaphorase activity, as described above, to examine the effect of NOS inhibitor on NADPH-diaphorase activity.

\section{Immunofluorescence staining}

Unfertilized MII oocytes and embryos were fixed in 3.7\% $(\mathrm{w} / \mathrm{v})$ paraformaldehyde in PBS overnight at $4^{\circ} \mathrm{C}$. The fixed specimens were permeabilized in $0.1 \%(\mathrm{v} / \mathrm{v})$ Triton-X100 in PBS for 15 min. Oocytes and embryos were rinsed in PBS, placed in blocking solution $(0.1 \%(\mathrm{w} / \mathrm{v}) \mathrm{BSA}$ and $0.01 \%$ (v/v) Tween 20 in PBS) for $15 \mathrm{~min}$ and then incubated for $1 \mathrm{~h}$ in blocking solution with primary antibody (100-fold dilution). The specimens were rinsed in blocking solution and incubated with secondary antibody (anti-rabbit immunoglobulin antibody conjugated to biotin) diluted 500 -fold in blocking solution for $30 \mathrm{~min}$ and then with FITC-conjugated streptavidin diluted 100-fold in blocking solution. The specimens were washed again and mounted on glass slides. Fluorescence of FITC was visualized by excitation at $488 \mathrm{~nm}$ with the argon laser on a confocal laser microscope (LSM-410; Carl Zeiss, Oberkochen), and oocytes and embryos were cut into $1 \mu \mathrm{m}$ sections. Primary antibodies were pretreated with blocking peptide for $1 \mathrm{~h}$ at room temperature before incubation with oocytes and embryos to determine the specificity of the primary antibodies. All the samples were processed and analysed together under the same conditions.

\section{Statistical analysis}

Experiments on the effects of NOS inhibitors on the development in vitro of one-cell embryos beyond the twocell stage and on the effect of L-NAME on the development in vitro of four-cell embryos to the blastocyst stage were repeated three times. Data were analysed by ANOVA and Fisher's protected least significant difference test. Percentage data were subjected to arcsine transformation before statistical analysis. A value of $P<0.05$ was considered to be significant.

\section{Results}

NOS activity of unfertilized oocytes and preimplantation embryos

The expression of NOS activities in mouse unfertilized MII oocytes and embryos was visualized during preimplantation development by cytochemical staining for the NADPH diaphorase activity of NOS, which reflects the distribution of the total enzyme activity in an egg. NADPH-diaphorase 
staining was observed in unfertilized MII oocytes and embryos during preimplantation stages. A substantial increase in staining was evident after fertilization (Fig. 1). After the two-cell stage, the intensity of staining decreased as development proceeded to the eight-cell stage. However, the staining intensity increased at the morula stage, and in particular staining of the inner cell population of compacted morula was stronger than that of the outer cell population (Fig. 1f). In early blastocysts, staining was much stronger in the inner cell mass (ICM) than in trophectoderm cells, whereas at the expanded blastocyst stage, staining was confined to the ICM (Fig. 1g,h). No reactive staining was observed in the control MII oocytes which were incubated in medium that did not contain $\beta$-NADPH (Fig. 1i).

\section{Expression and localization of eNOS and iNOS during preimplantation development}

As NOS activity was detected in unfertilized MII oocytes and preimplantation embryos, immunocytochemistry was used to determine whether NOS isoforms are expressed in oocytes and embryos. Expression of eNOS and iNOS was detected in oocytes and embryos during the preimplantation period (Fig. 2). eNOS protein was distributed either evenly or in fine granules in the cytoplasm and nuclei (except nucleoli) of embryos at the one-cell to blastocyst stages, whereas fluorescence intensity was weaker in the nuclei of embryos at the two-cell to blastocyst stages. iNOS protein was distributed either evenly or as fine granules in the cytoplasm of oocytes and embryos at the one-cell to blastocyst stages. Fluorescence was also observed in a granular pattern in cytoplasm of oocytes and embryos at the one-cell to morula stages. In embryos at the one-cell and two-cell stages, granular staining was distributed at the periphery or the perinuclear region of the cytoplasm. The staining intensity of iNOS in morula and blastocysts was weaker in the inner cell population and the ICM than in the outer cell population and the trophectoderm cells, respectively. After pretreatment of each primary antibody with the respective blocking peptide, nuclear and cytoplasmic fluorescence were not observed (Fig. 2h, panels A and $\mathrm{B}$ ), indicating that the staining was specific for each of the NOS proteins.

\section{Inhibitory effects of L-NAME on development of one-cell embryos beyond the two-cell stage in vitro}

The effects of the NOS inhibitors L-NAME, L-NIO and aminoguanidine were examined to investigate the role of NOS activity in the development of embryos in vitro during the preimplantation period. When one-cell embryos were treated with 1 mmol L-NAME I-1, the development of most of these embryos was arrested at the two-cell stage, whereas when one-cell embryos were cultured for 4 days in medium without L-NAME, most of these embryos developed to blastocysts (Table 1). The developmental arrest could be partially overcome by the concomitant addition of $1 \mathrm{mmol}$ L-arginine $\mathrm{I}^{-1}$ to the medium.
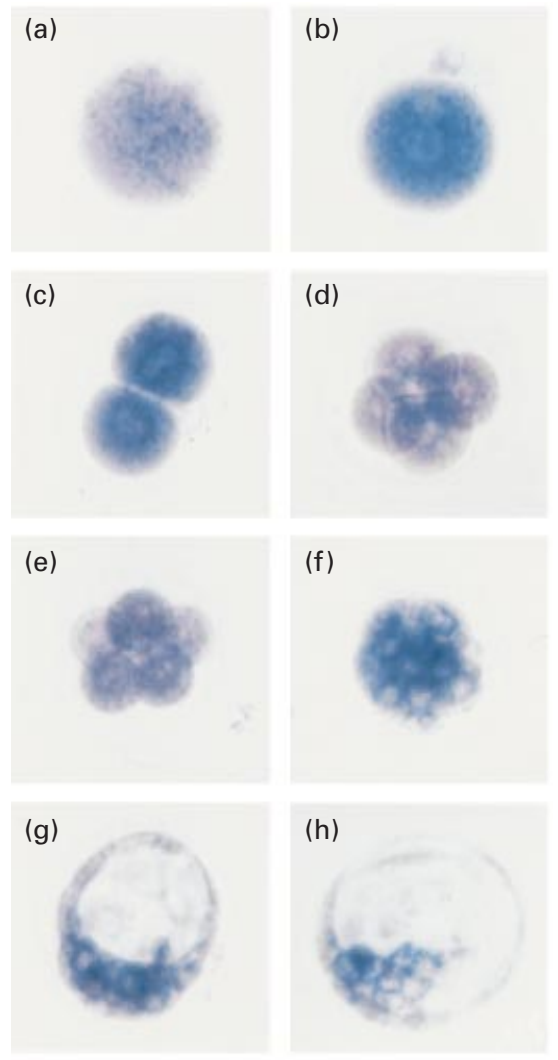

(i)

Fig. 1. NADPH-diaphorase staining in mouse oocytes at the second meiotic metaphase (MII) stage and in preimplantation mouse embryos. MII oocyte (a) and embryos at the one-cell (b), two-cell (c), four-cell (d), eight-cell (e), morula (f), early blastocyst (g) and expanded blastocyst (h) stages were incubated for $30 \mathrm{~min}$ at $37^{\circ} \mathrm{C}$ in $0.1 \mathrm{mmol}$ Tris- $\mathrm{HCl} \mathrm{I}{ }^{-1}, \mathrm{pH} 7.2$, containing $1 \mathrm{mmol} \beta$ $\mathrm{NADPH} \mathrm{I}^{-1}, 0.2 \mathrm{mmol}$ nitroblue tetrazolium $\mathrm{I}^{-1}$ and $0.2 \%(\mathrm{v} / \mathrm{v})$ Triton-X100. (i) MII oocyte stained in the incubation medium without NADPH (control). Twenty-four oocytes or embryos were analysed at each stage of development. The experiment was repeated three times and showed essentially the same results on each occasion. Scale bar represents $50 \mu \mathrm{m}$.

When NADPH-diaphorase activities of embryos at the early two-cell stage that developed from one-cell stage embryos in medium with or without 1 mmol L-NAME I-1 were compared, it was found that the staining intensity was decreased after treatment with L-NAME (Fig. 3). The concomitant addition of $1 \mathrm{mmol} \mathrm{L}$-arginine $\mathrm{I}^{-1}$ to cells treated with L-NAME attenuated the decrease of the staining intensity after L-NAME treatment (data not shown). These data indicate that inhibition of NOS activity by L-NAME resulted in the developmental arrest at the two-cell stage. 
(A)
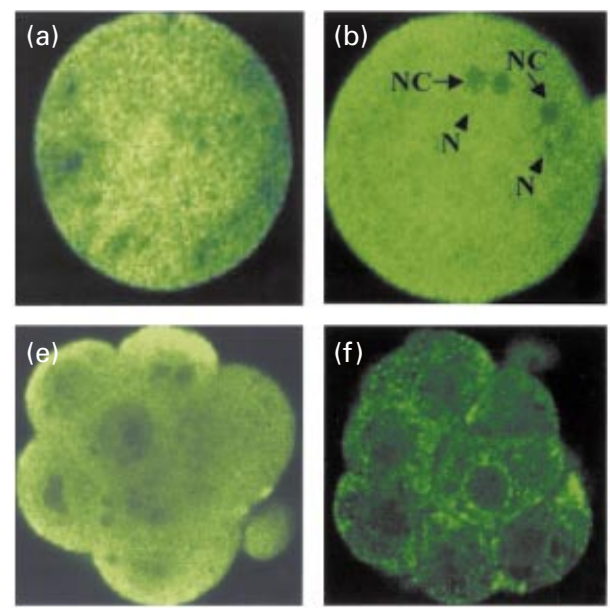

(B)
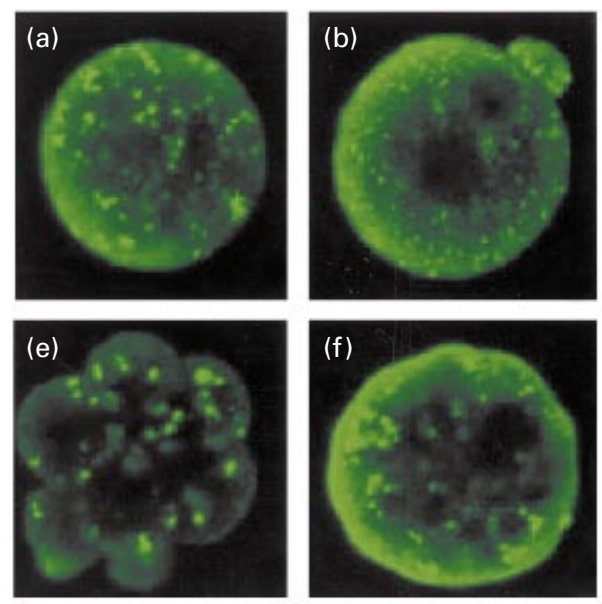
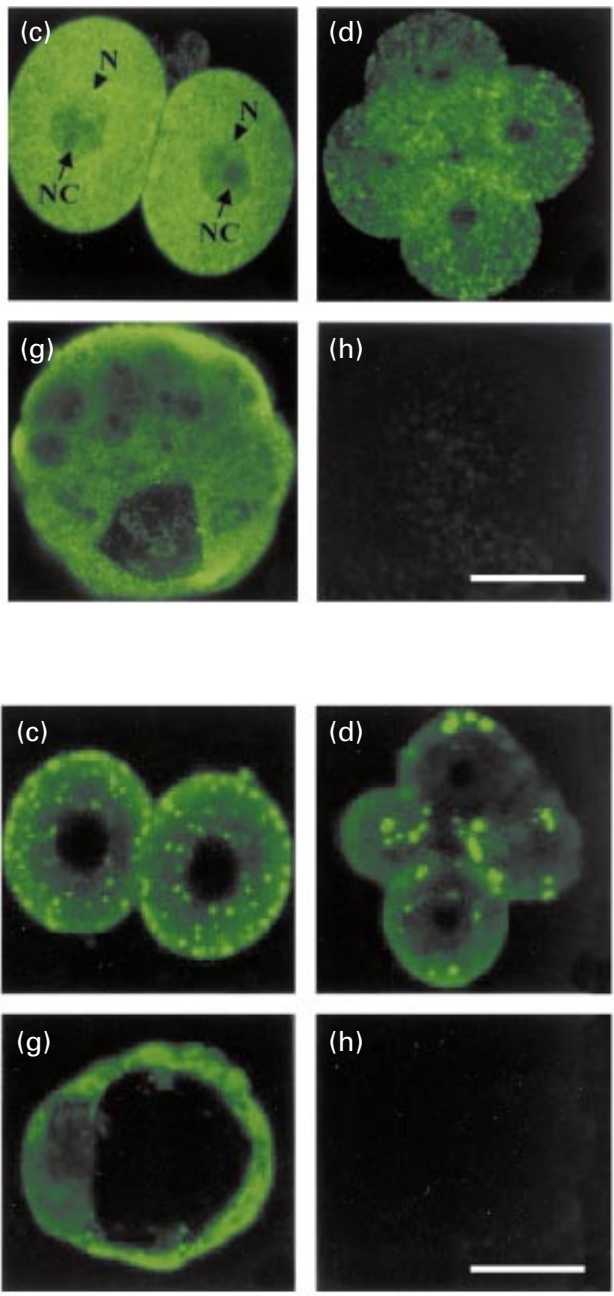

Fig. 2. Subcellular localization of endothelial nitric oxide synthase (eNOS) and inducible nitric oxide synthase (iNOS) proteins in mouse oocytes at the second meiotic metaphase (MII) stage (A) and in preimplantation mouse embryos (B), respectively. MII oocyte (a) and embryos at the onecell (b), two-cell (c), four-cell (d), eight-cell (e), morula (f) and blastocyst (g) stages were stained by indirect immunofluorescence using anti-eNOS antibody (A) or iNOS-antibody (B). (h) One-cell embryos (A and B) were stained with anti-eNOS or iNOS-antibody after pretreatment with their respective blocking peptides, respectively. Ten oocytes or embryos at each stage were observed in an optical section to bisect the nucleus. The experiment was repeated twice and showed similar results on each occasion. N (arrowhead): nucleus; NC (short arrow): nucleolus. Scale bars represent $50 \mu \mathrm{m}$.

Table 1. Effect of $N^{\omega}$-nitro-L-arginine methyl ester (L-NAME) on development of one-cell mouse embryos in vitro

\begin{tabular}{|c|c|c|c|c|c|c|}
\hline \multirow{2}{*}{$\begin{array}{l}\text { L-NAME } \\
\left(\mathrm{mmol} \mathrm{I}^{-1}\right)\end{array}$} & \multirow{2}{*}{ 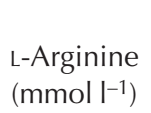 } & \multirow{2}{*}{$\begin{array}{c}\text { Number of } \\
\text { embryos } \\
\text { cultured }\end{array}$} & \multicolumn{4}{|c|}{ Number (\%) of embryos developed to } \\
\hline & & & Two-cell & Four-cell & Morula & Blastocyst \\
\hline 0 & 0 & 85 & $82(95)$ & $78(90)^{\mathrm{a}}$ & $75(86)^{\mathrm{a}}$ & $68(78)^{\mathrm{a}}$ \\
\hline 1 & 0 & 79 & $76(95)$ & $11(13)^{b}$ & $0(0)^{b}$ & $0(0)^{\mathrm{b}}$ \\
\hline 1 & 1 & 78 & $74(94)$ & $59(75)^{\mathrm{a}}$ & $53(71)^{\mathrm{a}}$ & $42(54)^{\mathrm{a}}$ \\
\hline
\end{tabular}

abValues with different superscripts in the same column are significantly different $(P<0.05)$. 
(a)

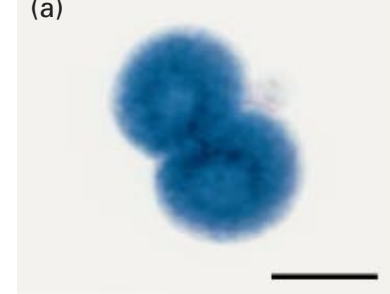

(b)

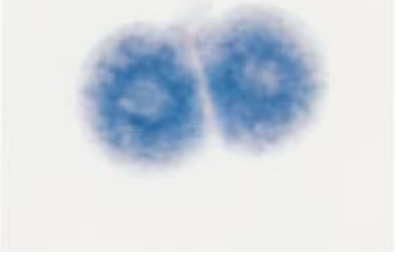

Fig. 3. Decrease of NADPH-diaphorase activity in embryos after treatment with $N^{\omega}{ }^{\omega}$-nitro-L-arginine methyl ester. NADPHdiaphorase staining was performed in embryos that developed to the two-cell stage in in vitro culture for $20 \mathrm{~h}$ after collection of one-cell embryos in medium without (a) or with (b) $1 \mathrm{mmol} \mathrm{N}^{\omega_{-}}$ nitro-L-arginine methyl ester $\mathrm{I}^{-1}$. Ten embryos were analysed in each group. The experiment was repeated three times and showed essentially the same results on each occasion. Scale bar represents $50 \mu \mathrm{m}$.

When four-cell embryos were cultured in medium with 1 mmol L-NAME I-1, the development to the blastocyst stage was not affected (Table 2). However, when one-cell embryos were cultured for 4 days in medium with or without L-NIO or aminoguanidine, addition of neither L$\mathrm{NIO}$ nor aminoguanidine caused developmental arrest at the two-cell stage, but blastocyst formation was inhibited at concentrations of $10 \mathrm{mmol} \mathrm{I}^{-1}$ and $2 \mathrm{mmol} \mathrm{I}^{-1}$, respectively (Table 3). However, as the addition of L-arginine did not induce development to the blastocyst stage (Table 3), it is likely that the inhibitory effects of L-NIO and aminoguanidine on the developmental transition from the morula to blastocyst stage were exerted through their non-specific deleterious actions.

\section{Discussion}

In the present study, the expression and activities of NOS in MII oocytes and preimplantation embryos of mice were investigated by immunofluorescence staining using antibodies against eNOS and iNOS, and by NADPHdiaphorase staining, respectively. In the NADPHdiaphorase staining experiments, two peaks of NOS activity were observed in embryos during the preimplantation period. The first peak occurred immediately after fertilization. The activities of NOS increased substantially and were higher in embryos at the one-cell and two-cell stages than in unfertilized MII oocytes and embryos at the four-cell and eight-cell stages. Kuo et al. (2000) also found an increase in the activity of NOS after fertilization in sea urchin eggs, and reported that NOS and NO-related bioactivities were necessary and sufficient for successful egg activation at fertilization. Therefore, it could be considered that the role of NOS and the related metabolism in egg activation is conserved through evolution from sea urchins to mammals. Furthermore, it is known that zygotic gene activation, that is, changing from maternal to embryonic transcriptional regulation, occurs in mouse
Table 2. Effect of $N^{\omega}{ }^{\omega}$-nitro-L-arginine methyl ester (L-NAME ) on the development of four-cell mouse embryos in vitro

\begin{tabular}{lccc}
\hline \multirow{2}{*}{$\begin{array}{l}\text { L-NAME } \\
\left(\text { mmol I }^{-1}\right)\end{array}$} & $\begin{array}{c}\text { Number of } \\
\text { embryos } \\
\text { cultured }\end{array}$ & Mumber (\%) of embryos developed to \\
\cline { 3 - 4 } & 82 & $78(95)$ & Blastocyst \\
\hline 0 & 82 & $68(83)$ & $68(83)$ \\
1 & & & $62(76)$ \\
\hline
\end{tabular}

embryos at the late one-cell to two-cell stages (Telford et al., 1990; Schultz, 1993), and that developmental arrest at the time when zygotic gene activation occurs is caused by disturbance of transcriptional activity or redox regulation in embryos at the one-cell and two-cell stages (Telford et al., 1990; Johnson and Nasr-Esfahani, 1994). In the present study, treatment of one-cell embryos with 1 mmol L-NAME I-1, which substantially decreased NOS activities, caused developmental arrest at the two-cell stage, but did not affect the first cleavage to the two-cell stage. In addition, treatment of mouse embryos at the one-cell stage with $\mathrm{N}$-acetylcysteine or pyrolidine dithiocarbamate, both of which are antioxidants, induced stage-specific developmental arrest at the two-cell stage (Nishikimi et al., 1999). These results indicate that oxygen free radical species, including NO, generated intracellularly, are required for the progression of mouse embryos through the two-cell stage and probably also for the transition between maternal and embryonic gene expression in mouse embryos.

The second peak of NOS activity occurred after cleavage. NOS activities were expressed mainly in the inner cell population of compacted morula and the ICM of blastocysts compared with the outer cell population and trophectoderm cells, respectively. At the expanded blastocyst stage, NOS activity decreased below the level of detection in trophectoderm cells. However, as blastocyst formation was not prevented by a specific NOS inhibitor, it seems likely that NOS activity is not associated with embryonic development during this period, although the possibility of an aberrant formation of blastocysts after LNAME treatment could not be excluded. In an attempt to eliminate this possibility, a further experiment would be required to investigate the numbers of ICM and trophectoderm cells by using differential staining of blastocysts cultured with or without L-NAME in the culture medium. However, recently, it has been reported that NOS and its related activities play a role in implantation and post-implantation development of early embryos (Novaro et al., 1997; Biswas et al., 1998; Saxena et al., 2000). Although NADPH-diaphorase activity was not detected in implanting embryos, intense activity was observed in trophectoderm cells of postimplantation stage embryos that were either lodged into the implantation chamber (in situ) or after culture (in vitro) (Gagioti et al., 2000). In addition, implantation rates in mice decreased markedly under higher doses of NO (Barroso et al., 1998). Moreover, NADPH- 
Table 3. Effects of $\mathrm{L}_{-} \mathrm{N}^{5}-(1$-iminoethyl)-ornithine ( $\mathrm{L}-\mathrm{NIO})$ and aminoguanidine (AG) on development of one-cell mouse embryos in vitro

\begin{tabular}{|c|c|c|c|c|c|c|}
\hline \multirow{2}{*}{ Treatment* } & \multirow{2}{*}{$\begin{array}{l}\text { L-Arginine } \\
\left(\mathrm{mmol} \mathrm{I}^{-1}\right)\end{array}$} & \multirow{2}{*}{$\begin{array}{c}\text { Number of } \\
\text { embryos cultured }\end{array}$} & \multicolumn{4}{|c|}{ Number (\%) of embryos developed to } \\
\hline & & & Two-cell & Four-cell & Morula & Blastocyst \\
\hline Control & 0 & 75 & $70(94)$ & $63(90)$ & $60(80)$ & $53(71)^{a}$ \\
\hline \multirow[t]{2}{*}{ L-NIO } & 0 & 80 & $76(95)$ & $70(88)$ & $63(79)$ & $4(5)^{b}$ \\
\hline & 1 & 46 & $47(96)$ & $43(88)$ & $36(74)$ & $1(2)^{b}$ \\
\hline \multirow[t]{2}{*}{ AG } & 0 & 75 & $76(95)$ & $70(88)$ & $63(79)$ & $8(11)^{b}$ \\
\hline & 1 & 67 & $61(91)$ & $55(82)$ & $55(82)$ & $8(12)^{b}$ \\
\hline
\end{tabular}

${ }^{*}$ Concentrations of L-NIO and AG were $10 \mathrm{mmol} \mathrm{I}^{-1}$ and $2 \mathrm{mmol} \mathrm{I}^{-1}$, respectively.

abValues with different superscripts in the same column are significantly different $(P<0.05)$.

diaphorase staining of expanded blastocysts appeared to be confined to ICM cells and was not observed in trophectoderm cells. Taken together, these findings indicate that the reduction of NOS activity in trophectoderm cells of preimplantation and implanting blastocysts might be required for normal implantation.

In the present study, immunofluorescence revealed that eNOS was localized uniformly in the MII oocyte cytoplasm, as described by Jablonka-Shariff and Olson $(1997,1998)$, and that during the preimplantation stage, the fluorescent signal was observed in nuclei and cytoplasm. However, it appeared that the nuclear signal was much weaker in the two-cell to blastocyst stages. The present study is the first to show that eNOS is present in the nuclei of preimplantation embryos. This finding is unexpected, as it is well established that eNOS is a membrane-bound protein found in endothelial cells and many other types of cell (Pollock et al., 1993; North et al., 1994; Powers et al., 1995; Jablonka-Shariff and Olson, 1997). However, it is not known whether the nuclear localization of eNOS is associated with the development of early cleavage stage embryos. iNOS was localized in the egg cytoplasm at the MII stage and throughout the preimplantation period. In particular, intense granular fluorescence signals were localized in the cytoplasm of oocytes and embryos up to the morula stage, and in blastocysts the fluorescence intensity was weaker in the ICM than in the trophectoderm cells. However, Saxena et al. (2000) showed that iNOS was expressed mainly in the ICM of blastocysts after hatching. Unfortunately, at present, any correlation between the amount and localization of the NOS activities and the two NOS isoforms cannot be explained.

Gouge et al. (1998) also demonstrated the importance of NOS in normal embryonic development of mouse preimplantation embryos. Their findings showed that nitrate and nitrite, metabolites of $\mathrm{NO}$, were detected in the conditioned medium of embryos cultured for $24 \mathrm{~h}$ in KSOM supplemented with $3 \mathrm{mmol}$-arginine $\mathrm{I}^{-1}$ using the Griess assay. However, in the present study, medium of embryos cultured with or without L-arginine did not reveal the presence of nitrite or nitrate using the Griess assay (data not shown). Athanassakis et al. (2000) reported that although production of $\mathrm{NO}$ by normal early stage embryos was not detectable by the Griess assay, stimuli toxic to the embryos, such as interferon $\gamma$, tumour necrosis factor $\alpha$ and lipopolysaccharide, significantly induced NO production by the embryos to a concentration that could be detected by the Griess assay in a manner that was correlated with the induction of the inducible or endothelial isoforms of NOS. Therefore, it seems likely that an extremely small amount of $\mathrm{NO}$ is required for physiological regulation of preimplantation development, but higher concentrations of $\mathrm{NO}$ generated in embryos play a potential role in early embryonic death.

Knockout mice for eNOS, iNOS and nNOS have been produced. Mature eNOS knockout females produce significantly fewer pups in each litter compared with heterozygote or wild-type females, because of a failure of ovulation and oocyte meiosis in eNOS knockout mice (Jablonka-Shariff and Olson, 1998). However, it is not obvious whether the lower maturation competence reaching the MIl stage of eNOS knockout oocytes was due to a significant reduction of $\mathrm{NO}$ production in the oocytes, as it might be very hard to detect $\mathrm{NO}$ in the medium of cultured mouse oocytes during the maturation period. However, it was found that both iNOS and nNOS knockout oocytes were normally ovulated and after fertilization they were capable of developing normally until birth (Huang et al., 1993; Wei et al., 1995). The present study showed that development of mouse embryos beyond the two-cell stage in vitro was completely inhibited by L-NAME, but L-NIO and aminoguanidine had no affect on development beyond this stage. L-NAME is generally known to have a higher potency in inhibiting eNOS than do L-NIO and aminoguanidine, both of which are relatively selective inhibitors for iNOS (Mandai et al., 1996; Wheeler et al., 1997; Kane et al., 2001). Therefore, these findings indicate that eNOS activity in mouse preimplantation embryos may play an important role in their development, especially in the transition from the two-cell stage to the four-cell stage.

This work was supported in part by a Grant-in-Aid for Scientific Research (No. 13660287) from the Ministry of Education, Science and Culture, Japan and the Association of Livestock Technology (Japan). 


\section{References}

Athanassakis I, Aifantis I, Baritakis S, Framakiotis V, Koumantakis E and Vassiliaolis S (2000) Nitric oxide production by preimplantation embryos in response to embryo toxic factors Cellular Physiology and Biochemistry 10 169-176

Barroso RP, Osuamkpe C, Nagamani M and Yallampalli C (1998) Nitric oxide inhibits development of embryos and implantation in mice Molecular Human Reproduction 4 503-507

Biswas S, Kabir SN and Pal AK (1998) The role of nitric oxide in the process of implantation in rats Journal of Reproduction and Fertility 114 157-161

Erbach GT, Lawitts JA, Papaioannou VE and Biggers JD (1994) Differential growth of the mouse preimplantation embryo in chemically defined media Biology of Reproduction 50 1027-1033

Gagioti S, Scavone C and Bevilacqua E (2000) Participation of the mouse implanting trophoblast in nitric oxide production during pregnancy Biology of Reproduction 62 260-268

Gouge RC, Marshburn P, Gordon BE, Nunley W and Huet-Hudson YM (1998) Nitric oxide as a regulator of embryonic development Biology of Reproduction 58 875-879

Griffith OW and Stuehr DJ (1995) Nitric oxide synthases: properties and catalytic mechanism Annual Review of Physiology 57 707-736

Huang PL, Dawson TM, Bredt DS, Snyder SH and Fishman MC (1993) Targeted disruption of the neuronal nitric oxide synthase gene Cell 75 $1273-1286$

Ignarro LJ (1990) Nitric oxide. A novel signal transduction mechanism for transcellular communication Hypertension 16 477-483

Jablonka-Shariff A and Olson LM (1997) Hormonal regulation of nitric oxide synthases and their cell-specific expression during follicular development in the rat ovary Endocrinology 138 460-468

Jablonka-Shariff A and Olson LM (1998) The role of nitric oxide in oocyte meiotic maturation and ovulation: meiotic abnormalities of endothelial nitric oxide synthase knock-out mouse oocytes Endocrinology 139 2944-2954

Johnson MH and Nasr-Esfahani MH (1994) Radical solutions and cultural problems: could free oxygen radicals be responsible for the impaired development of preimplantation mammalian embryos in vitro? BioEssays 16 1-38

Kane AJ, Barker JE, Mitchell GM, Theile DRB, Romero R, Messina A, Wagh M, Fraulin FOG, Morrison WA and Stewart AG (2001) Inducible nitric oxide synthase (iNOS) promotes ischaemic skin flap survival British Journal of Pharmacology 132 1631-1638

Kuo RC, Baxter GT, Thompson SH, Stricker SA, Patton C, Bonaventura J and Epel D (2000) NO is necessary and sufficient for egg activation at fertilization Nature 506 633-636

Kuzin B, Roberts I, Peunova N and Enikolopov G (1996) Nitric oxide regulates cell proliferation during drosophila development Cell $\mathbf{8 7}$ 639-649
Mandai M, Mittag TW, Kogishi J, Iwaki M, Hangai M and Yoshimura N (1996) Role of nitric oxide synthase isoenzymes in endotoxin-induced uveitis Investigative Ophthalmology \& Visual Science 37 826-832

Moncada S, Palmer RM and Higgs EA (1991) Nitric oxide: physiology, pathophysiology and pharmacology Pharmacological Reviews 43 109-142

Nishikimi A, Mukai J and Yamada M (1999) Nuclear translocation of nuclear factor kappa B in early 1-cell mouse embryos Biology of Reproduction 60 1536-1541

North AJ, Star RL, Brannon TS, Ujiie K, Wells LB, Lowenstein CJ, Snyder SH and Shaul PW (1994) Nitric oxide synthase type I and type III gene expression are developmentally regulated in rat lung American Journal of Physiology 266 L635-L641

Novaro V, Gonzalez E, Jawerbaum A, Rettori V, Canteros G and Gimeno MF (1997) Nitric oxide synthase regulation during embryonic implantation Reproduction, Fertility and Development 9 557-564

Pollock JS, Nakane M, Buttery LD, Martinez A, Springall D, Polak JM, Forstermann U and Murad F (1993) Characterization and localization of endothelial nitric oxide synthase using specific monoclonal antibodies American Journal of Physiology 265 C1379-C1387

Powers RW, Chen L, Russell PT and Larsen WJ (1995) Gonadotropinstimulated regulation of blood-follicle barrier is mediated by nitric oxide American Journal of Physiology 269 E290-E298

Saxena D, Purohit SB, Kumer GP and Laloraya M (2000) Increased appearance of inducible nitric oxide synthase in the uterus and embryo at implantation Nitric Oxide 4 384-391

Schultz RM (1993) Regulation of zygotic gene activation in the mouse BioEssays 15 531-538

Telford NA, Watson AJ and Schultz GA (1990) Transcription from maternal to embryonic control in early mammalian development: a comparison of several species Molecular Reproduction and Development 26 90-100

Wang W, Inoue N, Nakayama T, Ishii M and Kato T (1995) An assay method for nitric oxide synthase in crude samples by determining product NADP Analytical Biochemistry $20274-280$

Wei XQ, Charles IG, Smith A, Ure J, Feng GJ, Huang FP, Xu D, Muller W, Moncada S and Liew FY (1995) Altered immune responses in mice lacking inducible nitric oxide synthase Nature 375 408-411

Wheeler MA, Smith SD, Garcia-Cardea G, Nathan CF, Weiss RM and Sessa W (1997) Bacterial infection induces nitric oxide synthase in human neutrophils Journal of Clinical Investigation 99 110-116

Received 10 May 2001

First decision 27 June 2001.

Accepted 14 August 2001. 